\title{
Heat and Moisture Exchangers and Humidification Efficacy in Pediatrics: Effects of Ventilator Settings and ETT Leakage
}

\author{
Alan de Klerk ${ }^{1}$ and Antonio M. Esquinas ${ }^{2}$ \\ ${ }^{1}$ Department of Neonatology/BirthCare Center, Florida Hospital Memorial Medical Center, 301 Memorial Medical Parkway, \\ Daytona Beach, FL 32114, USA \\ ${ }^{2}$ Intensive Care Unit, Hospital Morales Meseguer, Avenida Marques de Los Velez s/n, 30008 Murcia, Spain
}

Correspondence should be addressed to Alan de Klerk, adeklerk@earthlink.net

Received 14 June 2012; Accepted 3 July 2012

Copyright ( $) 2012$ A. de Klerk and A. M. Esquinas. This is an open access article distributed under the Creative Commons Attribution License, which permits unrestricted use, distribution, and reproduction in any medium, provided the original work is properly cited.

Heat and moisture exchangers (HMEs) have been increasingly used for humidification during mechanical ventilation in pediatric patients [1]. However, efficacy of HMEs in the pediatric population has not yet been fully evaluated and there is limited information in the literature regarding the effects of ventilator settings and endotracheal tube (ETT) leakage on the humidification performance of HMEs.

Chikata et al. [2] tested ten pediatric HMEs in a model lung, measuring performance under different respiratory rates, tidal volumes TVs (achieved with different pressure control levels), and leakage conditions. They found that eight of the ten HMEs maintained absolute humidity $(\mathrm{AH})$ at more than $30 \mathrm{mg} / \mathrm{L}$, the minimum level recommended by the American Association for Respiratory Care (AARC). With a small leak, AH decreased below $30 \mathrm{mg} / \mathrm{L}$ (26.6 to $29.5 \mathrm{mg} / \mathrm{L}$ ), decreasing further (19.7 to $27.3 \mathrm{mg} / \mathrm{L}$ ) with a larger leak. Pressure control (tidal volume) level did not statistically significantly affect $\mathrm{AH}$ values, although there was a trend to decreased $\mathrm{AH}$ at higher tidal volumes. In three of the HMEs, increased respiratory rate resulted in a significantly higher $\mathrm{AH}$. In six of the other seven HMEs, there was a nonstatistically significant trend to higher $\mathrm{AH}$ with increased respiratory rate, with one HME showing a nonsignificant trend to lower $\mathrm{AH}$.

We think this is a well-designed and conducted study and provides valuable information regarding the use of HMEs in pediatric patients under different conditions. The effect of ETT leakage on AH is nicely demonstrated and is consistent with previously published data on mechanically ventilated adults.
However, we had some questions regarding the study's other findings and their possible explanation as follows

(1) the study found that 8 out of 10 pediatric HMEs maintained $\mathrm{AH}$ at more than $30 \mathrm{mg} / \mathrm{L}$, while they quote the Luchetti et al. [3] study they reference as showing "AH of less than $28 \mathrm{mg} / \mathrm{L}$ in all HMEs used with pediatric patients" despite using similar oneway valve methodology in their circuit to prevent mixing of inspired and expired gases? This finding is even more puzzling given that one of the two HMEs used in the Luchetti study, the Hygroboy (Covidien [formerly Tyco Healthcare], Mirandola, Italy), in the present study was found to produce the highest $\mathrm{AH}$ $(32.4 \mathrm{mg} / \mathrm{L})$ of the ten HMEs tested. How is this difference in findings between the 2 studies of the same HME explained?

(2) the finding that increased respiratory rates resulted in a trend to higher $\mathrm{AH}$ that reached significance in 3 of the tested humidifiers is interesting. Previous studies of HMEs in adults and children have found lower $\mathrm{AH}$ associated with higher tidal volumes $[4,5]$ and minute volumes (MVs) $[1,6,7]$. It would seem more logical that an increasing respiratory rate presumably would result in a higher MV, with resultant lower $\mathrm{AH}$, but Chikata et al. found the opposite. The authors did not comment on this in their paper, and we wonder if they have a plausible explanation for this;

(3) finally, the authors speculate that the finding of a linear relationship between increasing dead space 
and increasing $\mathrm{AH}$ might possibly be related to improved humidification in those HMEs with larger internal volume and dead space. Since it is generally recommended to minimize dead space with HMEs, in particular in pediatric use, would the authors care to comment on striking a balance between maximizing humidification capacity and minimizing dead space?

\section{Abbreviations}

AH: Absolute humidity

HMEs: Heat and moisture exchangers

TV: Tidal volume.

\section{References}

[1] J. J. J. Lucato, A. B. Adams, R. Souza, J. A. Torquato, C. R. R. Carvalho, and J. J. Marini, "Evaluating humidity recovery efficiency of currently available heat and moisture exchangers: A respiratory system model study," Clinics, vol. 64, no. 6, pp. 585-590, 2009.

[2] Y. Chikata, C. Sumida, J. Oto, H. Imanaka, and M. Nishimura, "Humidification performance of heat and moisture exchangers for pediatric use," Critical Care Research and Practice, vol. 2012, Article ID 439267, 5 pages, 2012.

[3] M. Luchetti, A. Pigna, A. Gentili, and G. Marraro, "Evaluation of the efficiency of heat and moisture exchangers during paediatric anaesthesia," Paediatric Anaesthesia, vol. 9, no. 1, pp. 39-45, 1999.

[4] N. Ünal, J. K. K. Kanhai, S. L. C. E. Buijk et al., "A novel method of evaluation of three heat-moisture exchangers in six different ventilator settings," Intensive Care Medicine, vol. 24, no. 2, pp. 138-146, 1998.

[5] H. Schiffmann, "Humidification of Respired Gases in Neonates and Infants," Respiratory Care Clinics of North America, vol. 12, no. 2, pp. 321-336, 2006.

[6] C. Martin, L. Thomachot, B. Quinio, X. Viviand, and J. Albanese, "Comparing two heat and moisture exchangers with one vaporizing humidifier in patients with minute ventilation greater than $10 \mathrm{~L} / \mathrm{min}$," Chest, vol. 107, no. 5, pp. 1411-1415, 1995.

[7] C. Martin, L. Papazian, G. Perrin, P. Bantz, and F. Gouin, "Performance evaluation of three vaporizing humidifiers and two heat and moisture exchangers in patients with minute ventilation > $10 \mathrm{~L} / \mathrm{min}$," Chest, vol. 102, no. 5, pp. 1347-1350, 1992. 


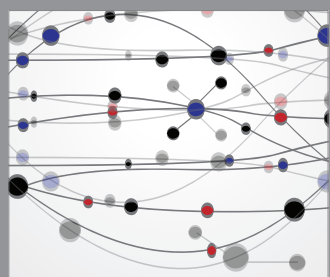

The Scientific World Journal
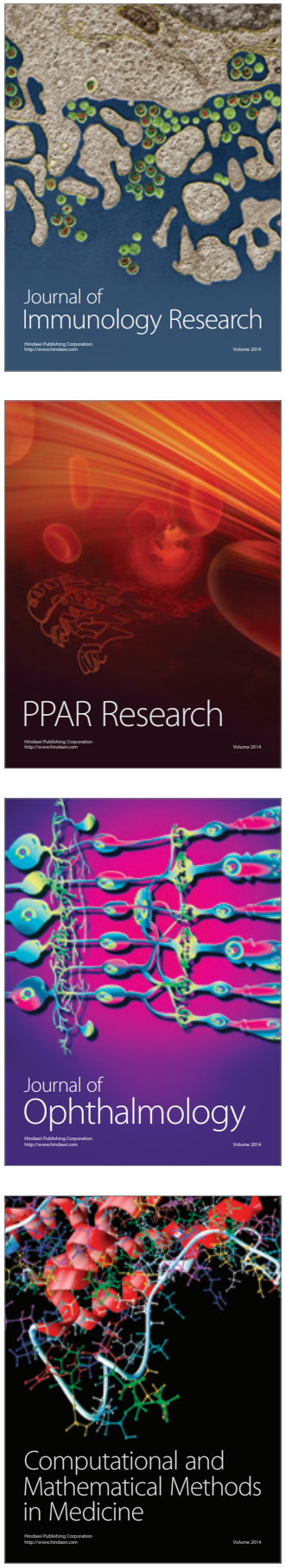

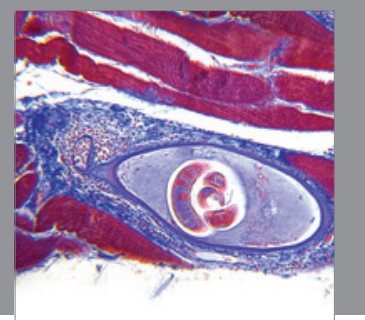

Gastroenterology

Research and Practice
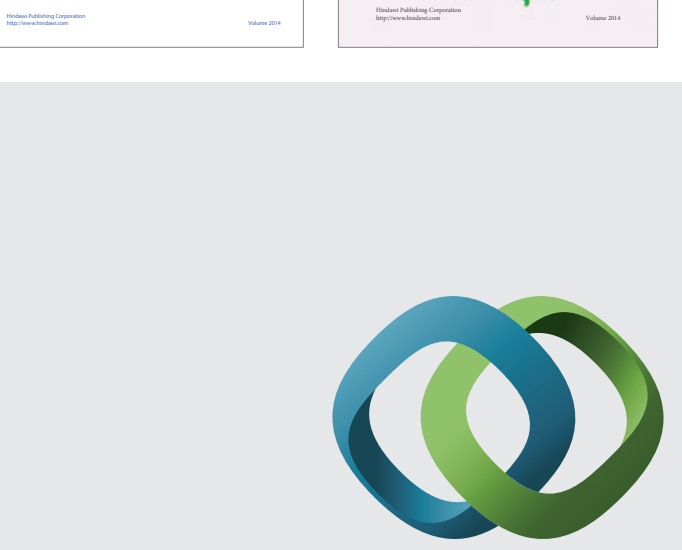

\section{Hindawi}

Submit your manuscripts at

http://www.hindawi.com
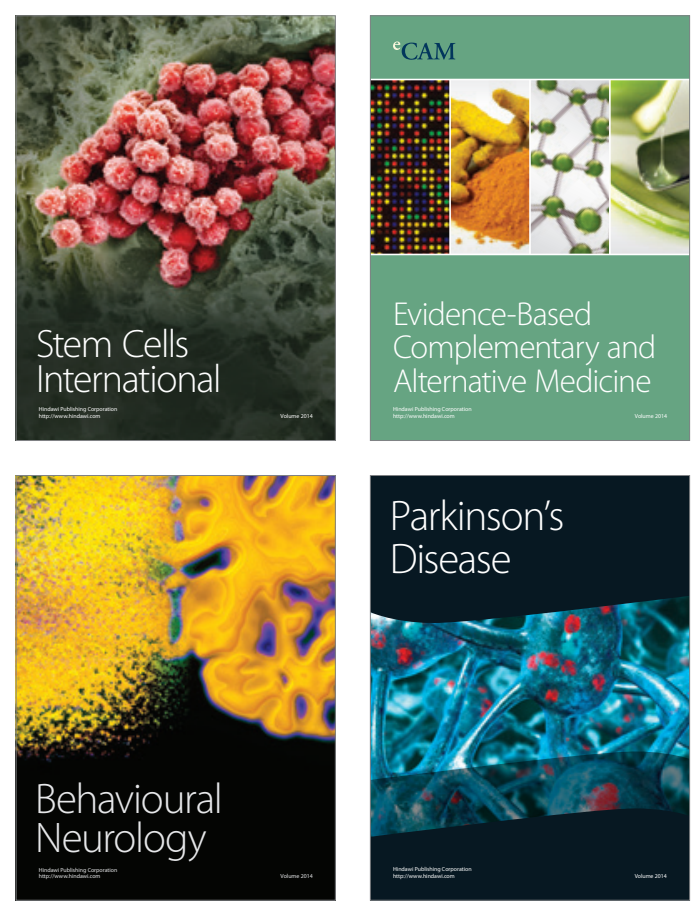

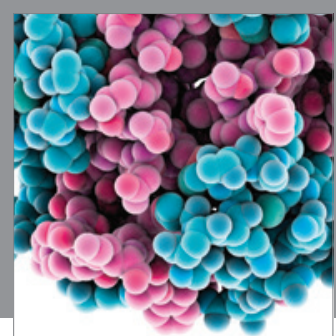

Journal of
Diabetes Research

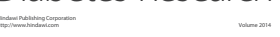

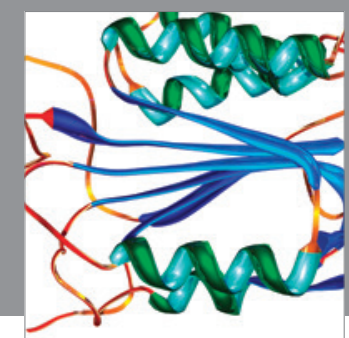

Disease Markers
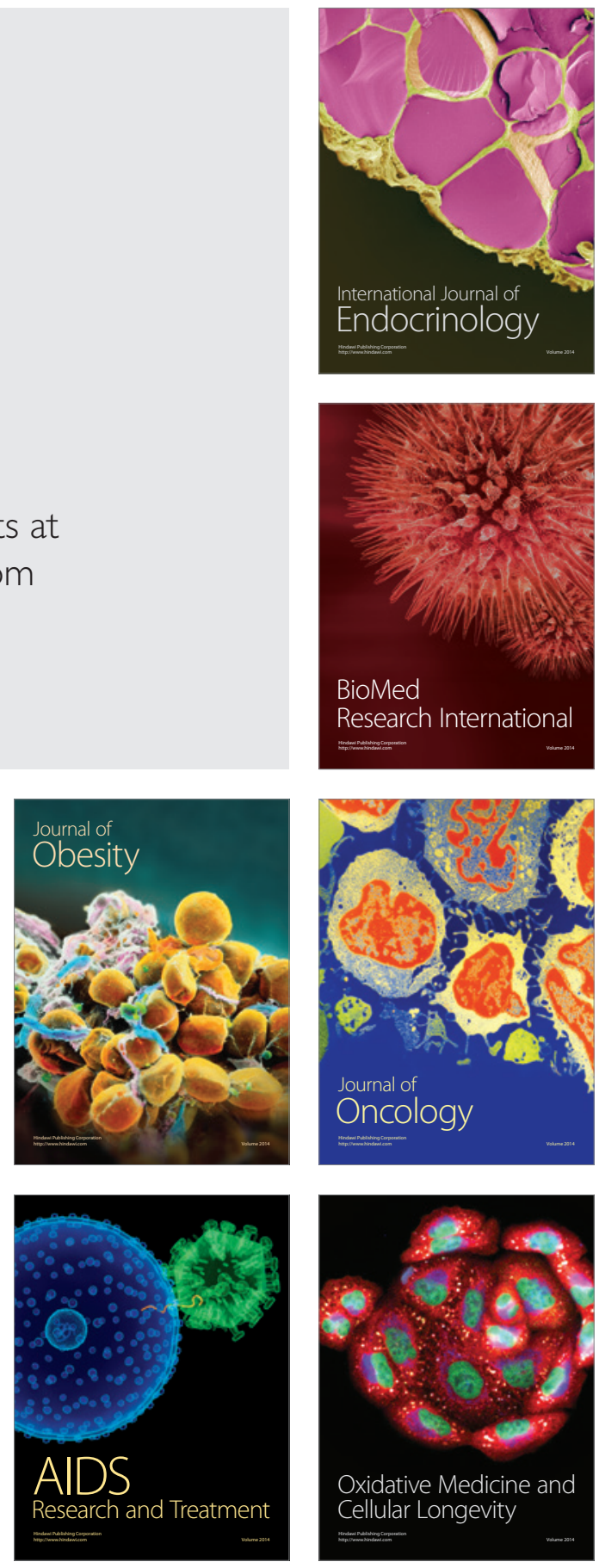